\title{
PROPOSTA DE CUIDAR COM ENFOQUE EDUCATIVO ÀS MÃES EM ALEITAMENTO MATERNO ${ }^{1}$
}

\author{
A PROPOSAL OF NURSING CARE WITH AN EDUCATIONAL FOCUS FOR \\ BREASFEEDING MOTHERS \\ PROPUESTA DE CUIDADOS A LAS MADRES EN PERÍODO DE \\ AMAMANTACIÓN BAJO UNA PERSPECTIVA EDUCATIVA
}

\author{
Palmira Soares do Rozário ${ }^{2}$ \\ Ivete Palmira Sanson Zagonel ${ }^{3}$
}

\begin{abstract}
RESUMO: Trabalho realizado em uma instituição hospitalar de Curitiba, o qual objetivou a implementação de uma proposta de cuidar com enfoque educativo às mães em aleitamento materno com o efetivo envolvimento da equipe de enfermagem da unidade de alojamento conjunto. Para alcançar essa meta, utilizei como referencial teórico as idéias de Watson (1979). A metodologia embasou-se na operacionalização de todas as fases que compõem o processo de enfermagem. A construção dos conceitos, implementação da sistematização do cuidado e avaliação do caminhar, possibilitaram delinear o marco conceitual. Através do desenvolvimento destas etapas, efetivaramse os encontros com as mães e a equipe de enfermagem, os quais serviram também para a coleta de dados. Os dados foram analisados de forma qualitativa. O estudo foi realizado com 15 mães. Foi possível desvelar suas dificuldades, desejos, ansiedades, frustrações, emoções, expectativas, medos, dúvidas, conclusões antecipadas, insegurança, desânimo, satisfação, indiferença, durante o desenvolvimento do trabalho.
\end{abstract}

PALAVRAS-CHAVE: aleitamento materno, cuidado de enfermagem, processo de enfermagem

\section{INTRODUÇÃo}

Dada a importância incontestável do tema que aborda a prática educativa realizada pela equipe de enfermagem às mães que experienciam o processo de aleitamento materno, assim como, considerando a responsabilidade profissional de atuação nesta área, é que sou incentivada a aprofundar e desvelar a temática. A motivação tem como elemento propulsor a contribuição que posso efetivar em relação ao aleitamento materno às mães na instituição que trabalho, assim como a extensão da mesma a outras comunidades.

O aleitamento materno é um processo natural, como afirmam Valdés, Sánchez e Labbok (1996), mas nem por isso, é um ato instintivo ou inato. Nesse sentido, entendo que amamentar é uma habilidade que necessita ser resgatada, uma prática que precisa ser reaprendida e intensamente apoiada. É importante considerar que nem todas as mães que amamentam recebem as orientações necessárias para o completo entendimento e assimilação desta prática

\footnotetext{
${ }^{1}$ Monografia apresentada como requisito parcial de conclusão do Curso de Especialização em Projetos Assistenciais - modalidade à distância da UFPR.

${ }^{2}$ Enfermeira. Chefe da Unidade de Alojamento Conjunto de Instituição Hospitalar Pública de Curitiba. Especialista em Projetos Assistenciais - modalidade à distância da UFPR.

${ }^{3}$ Enfermeira. Professora Adjunto do Departamento de Enfermagem da UFPR. Doutora em Filosofia de Enfermagem. Área de atuação materno-infantil. Coordenadora do NEPECHE (Núcleo de Estudos, Pesquisa e Extensão em Cuidado Humano de Enfermagem/UFPR).
} 
tão singular a cada mulher.

No Brasil, em especial na última década, os fundamentos da assistência de enfermagem em aleitamento materno, bem como a atitude dos profissionais que atuam na área, têm se modificado em decorrência dos resultados de pesquisa, do próprio desenvolvimento da profissão e também em função do movimento pró-amamentação, iniciado no país em 1981. Tais modificações são perceptíveis nos diversos níveis de atuação profissional, ou seja, no ensino, pesquisa e assistência. Para Santos (1991), com relação ao ensino, embora a literatura apresente lacunas importantes quanto à análise dos conteúdos ministrados nas diversas escolas de enfermagem do país, é possível perceber na prática, que os currículos de enfermagem já não padecem mais da chamada "doença curricular" onde o tema aleitamento materno quando não ausente, era abordado de forma superficial e pouco relevante. Com relação à pesquisa e à produção científica, embora longe do ideal, a literatura mostra que tanto a enfermagem internacional quanto a brasileira, tem investido tempo e esforços consideráveis em relação ao estudo da amamentação. Nos últimos anos avolumam-se publicações sobre o tema e importantes contribuições têm sido dadas por enfermeiras que atuam na área.

Na prática, a experiência vivida como enfermeira, tem me revelado que os conhecimentos acima citados se constituem em pré-requisitos básicos para a prestação de um cuidado adequado, entretanto muitos outros fatores como os sócio-culturais, políticos, econômicos e demográficos também merecem ser considerados. Diante dessa contextualização, proponho o tema, por considerar que seu aprofundamento poderá contribuir significativamente com a profissão, com a cliente e sua família. Considero que este projeto assistencial poderá subsidiar e despertar na equipe de enfermagem a motivação, a satisfação, o encanto em atuar junto às mães em processo de aleitamento materno. Assim, objetivou-se implementar uma proposta de cuidar com enfoque educativo às mães em aleitamento materno com o efetivo envolvimento da equipe de enfermagem. Entre as estratégias para alcançar tal proposta, situa-se a construção de um marco conceitual para guiar a implementação do cuidado e a utilização de metodologia de cuidado de enfermagem com enfoque educativo às mães em aleitamento materno à luz das idéias de Watson (1979).

\section{A PRÁTICA EDUCATIVA ENQUANTO INSTRUMENTO DE CUIDADO}

Considerando a importância do aleitamento materno tanto para a mãe como para o recém-nascido e observando o desinteresse e desconhecimento dessa prática por muitas mães, foi que optei pela abordagem de educação em saúde, com a finalidade de ajudar no resgate desse processo, através da prática educativa. A opção pela palestra educativa é vista como uma forma de esclarecimento e auxílio às mães, sendo que durante o decorrer da mesma, há a oportunidade de expressar suas ansiedades, suas dúvidas, enfim, ficarem livres para qualquer questionamento, estabelecendo-se a inter-relação compartilhada. Durante o processo ensinoaprendizagem, a enfermagem tem contato mais próximo com as mães e nesse momento tem a oportunidade de detectar as dificuldades de cada cliente, pois nem todas as mães recebem orientações durante o pré-natal. Percebe-se que muitas clientes apenas ouvem as orientações, porém não ocorre a educação consciente sobre esse processo, tão importante neste momento de suas vidas. A conscientização vai além do repasse simples de informações, exige o envolvimento efetivo das clientes às orientações recebidas. Considero que, somente um processo de ensino-aprendizagem que conduza à conscientização, poderá modificar hábitos adquiridos, a fim de implementar a prática do aleitamento materno com qualidade e conseguir resultados satisfatórios à mãe e ao filho.

Na realidade em que atuo, para a efetivação das ações educativas, são utilizados vários materiais de apoio, indispensáveis para a orientação às mães, como, seio cobaia, álbum seriado, boneca, lâmpada, seringas, chá preto em saquinho, gaze etc. A equipe considera a educação 
em saúde uma metodologia eficiente, pois facilita a comunicação entre equipe e clientes. 0 processo de comunicação interpessoal é extremamente importante, auxiliando na obtenção de resultados satisfatórios. As ações educativas contribuem para a melhoria do conhecimento, porém necessitam um contínuo aprimoramento e desenvolvimento diante de novos problemas do cotidiano, relacionados à questão do aleitamento materno, bem como envolvimento da equipe do turno noturno, gradativamente. Tendo os membros da equipe de enfermagem do turno diurno sentido a necessidade de mudança na forma de realizar a educação em saúde no puerpério, optou-se em discutir o tema "a alteração da rotina de trabalho". Até o momento de realização deste encontro reflexivo com a equipe, as orientações sobre aleitamento materno não eram efetivadas de forma individual, resultando assim um conhecimento desigual entre as puérperas. Assim, a partir da efetivação do encontro em que se discutiu a "alteração da rotina de trabalho", os membros da equipe de enfermagem sentem-se mais satisfeitos e já é possível perceber a motivação em implementar o novo modo de atuar. Bagnato, Cocco e Sordi (1999) estabelecem como importante a sensibilidade, a fim de compreender a educação em suas diferentes dimensões permitindo aos profissionais considerar a realidade atual contextualizada, inclusive em relação à saúde e assumir uma postura política profissional que contribua para dar respostas às necessidades e demandas de saúde da população.

Na visão de Freire (1997, p.25) "...ensinar não é transferir conhecimento, mas criar a possibilidade para a sua produção ou a sua construção", e "quem ensina aprende ao ensinar e quem aprende ensina ao aprender". Essas concepções mostram que o processo educativo é um caminho de mão-dupla, envolvendo enfermeiro e auxiliar de enfermagem/cliente numa relação de colaboração e respeito à maneira insubstituível de existir de cada um com suas marcas próprias, com suas trajetórias de vida e suas experiências. As práticas educativas em saúde têm estado presentes no cotidiano dos profissionais de saúde e usuários dos serviços de saúde, como salienta Cocco (1991), porém não conseguem gerar grandes transformações que tenham impacto no modo de vida da população, em suas condições de saúde e na construção de sua cidadania. A autora considera as práticas educativas numa perspectiva ampla como uma das possibilidades fundamentais para a discussão da qualidade de vida, que é e continuará sendo um dos grandes desafios para as próximas décadas pois as desigualdades sociais ainda persistem. Segundo a autora, o que se tem encontrado na prática profissional é a visão das relações entre educação e saúde como algo compartimentalizado, visto sob a ótica da instituição e/ou do profissional de saúde onde a clientela participa das práticas educativas, com a perspectiva de um determinado tipo de troca, que não é uma troca responsável de saberes e interesses entre profissionais e clientes, porém de uma participação desta clientela em troca de medicamentos e/ou um atendimento "diferenciado" por parte dos profissionais vinculados ao grupo.

\section{O CUIDADO HUMANO À LUZ DAS IDÉIAS DE WATSON}

"A arte do cuidado de enfermagem começa quando a enfermeira, com a intenção de unir-se ao outro, revela externamente o sentimento de cuidado e preocupação". Desta forma ocorre a formação de um campo fenomenológico que integrará uma vivência subjetiva entre o ser que cuida e aquele que é por ele cuidado, conforme Watson, referido por Wolff (1996, p. 17).

Nunes e Zagonel (1996), embasadas nas idéias de Watson, afirmam que o conhecimento de enfermagem tem sido desenvolvido através de várias correntes filosóficas e teóricas de enfermagem que em um grande esforço através da história, tem perseguido o crescimento e aprimoramento deste conhecimento. Referem que desde Nightingale, em 1859, até os cientistas enfermeiros contemporâneos, o desvelamento e as influências dos paradigmas de enfermagem, têm contribuído para a construção da ciência de enfermagem, com definições de princípios teóricos e metodológicos, formas de implementação e instrumentalização através do conjunto 
de crenças, valores e leis de cada teórico. As autoras afirmam que nesta perspectiva, Watson propõe uma filosofia, ciência e arte de enfermagem, onde as idéias e ideais associados formam a teoria do cuidado humano. Assim, o desenvolvimento mental-espiritual do eu e do outro proposto por Watson (1979), bem como a descoberta da força interior e auto-controle através do cuidado, realiza-se pela interação inter-transpessoal. Esta transação de cuidado humano não vem sendo realizada de forma articulada, nutrida ou reconhecida como fundamental para o processo de cuidar profissional, porque a enfermagem tem focalizado sua atuação muito voltada à matéria e à forma. O paradigma do cuidado fundamenta-se no respeito profundo pela existência humana, nos mistérios e descobertas da vida e toda a inter-relação entre eles. $\bigcirc$ cuidado transpessoal acontece quando duas pessoas se encontram espontaneam̉ente em um determinado momento ou em uma situação, dependendo da maneira intersubjetiva e do campo fenomenológico gerado pela energia daquele encontro. A relação alcança a dimensão espiritual, cósmica, de doação em que existe preocupação pelo processo de cuidado e de "healing". A ação do enfermeiro é, portanto, reconhecer, facilitar e utilizar a consciência do poder do ser humano que envolve mente e espírito (Watson, 1979).

No aleitamento materno a enfermagem está engajada como co-participante nas transações de cuidado humano, propiciando às mães a possibilidade de progredir para níveis mais elevados de consciência em relação à promoção e manutenção do processo de lactação. Nesta situação, a enfermagem é visualizada como ciência e arte. Como ciência, a enfermagem refere-se à forma de ajudar, apoiar e incentivar as mães na promoção e manutenção do aleitamento materno por um período mínimo desejável de seis meses, através de uma efetiva relação interpessoal. Os objetivos a serem alcançados através desta relação, devem estar claros para o profissional e mãe e isto deverá ser facilitado através de relações humanas onde ambas se comprometam a desenvolver juntas. Como arte, a enfermagem na prática do aleitamento materno, refere-se à habilidade apresentada pela enfermeira em assistir às mães através de ações de planejamento, provisão e gerenciamento dos sistemas de cuidado humano, com o objetivo de desenvolver ou manter o funcionamento integral da mesma num certo nível de efetividade, tornando-a também capaz de enxergar e valorizar a importância do aleitamento materno. Isto requer e exige da enfermeira, um conhecimento profundo das variáveis e fatores que influenciam a mãe nesta prática para que, através das investigações e das análises criativas, possa empreender esforços para obtenção de resultados efetivos na promoção do aleitamento materno.

A escolha dessa teoria deveu-se ao fato de minha identificação com suas idéias. Como ela defende o cuidado humanizado, a teoria colabora com a realidade do meu dia-a-dia. Percebo que no meu local de trabalho é praticado o cuidado humanizado, porém não é reconhecido ainda pela equipe como tal.

O alvo do meu trabalho é o ser mãe que amamenta. A instrumentalização da equipe através do cuidado serve como subsídio para alcançar o ser humano - sujeito deste estudo. 0 estudo realizou-se em uma instituição hospitalar pública mantida com parceria entre Estado, Prefeitura Municipal, Universidade Federal do Paraná e Fundação da Universidade Federal do Paraná para o Desenvolvimento da Ciência, da Tecnologia e da Cultura (FUNPAR). Atende a clientela do município e região metropolitana de Curitiba. Todos os atendimentos são realizados pelo SUS. Possui 165 leitos distribuídos entre as várias especialidades.

\section{OPERACIONALIZANDO O CUIDADO DE ENFERMAGEM À MÃE EM ALEITAMENTO MATERNO}

A sistematização do cuidado embasada no marco conceitual ocorreu em três fases : construindo os conceitos; implementando a sistematização do cuidado e avaliando a caminhada da prática. Para a construção do marco conceitual, o qual envolve conceitos relacionados à minha prática profissional em aleitamento materno, idealizei a discussão em grupos. Inicialmente 
delineamos com a equipe de enfermagem do alojamento conjunto quais os conceitos mais importantes que comporiam o marco - $\mathbf{1}^{\mathbf{a}}$ fase. Decidiu-se que os conceitos de enfermagem, cliente, ambiente, saúde-doença, aleitamento materno e educação em saúde, seriam aqueles que dariam o impulso para a discussão. Traçamos um calendário de encontros, envolvendo a equipe de enfermagem, dos turnos diurno e noturno, em horários distintos (diurno e noturno), os quais totalizaram dezessete pessoas. A flexibilidade dos horários para a realização dos encontros contribuiu para a participação de grande parte dos elementos da equipe. Esta flexibilização tornou o processo mais trabalhoso, pois o mesmo tema foi discutido várias vezes. É importante salientar que os conceitos foram validados junto ao grupo, sempre no próximo encontro àquele em que havia sido realizada a discussão.

A partir da construção dos conceitos que compõem o marco conceitual deste trabalho, os quais foram discutidos e refletidos, passo a expor como se efetivou a implementação do marco em minha vivência cotidiana. $\mathrm{Na} \mathbf{2}^{\mathrm{a}}$ fase do processo, iniciei o contato com as clientesmães em aleitamento materno na própria unidade de internação, momento em que me apresentei e comentei sobre os objetivos de estar ali e do trabalho que estava desenvolvendo, bem como da importância de sua participação e colaboração. Foi solicitado consentimento livre e esclarecido a todos os participantes, o qual foi assinado antes de iniciar a coleta de informações. Para a obtenção dos dados, idealizei um roteiro-guia que auxiliou na interação enfermeiro-cliente, bem como desencadeou o diálogo. Com o roteiro em mãos utilizei a entrevista junto às clientes. Iniciava-se o desvelamento da cliente / mãe em aleitamento materno. O histórico de enfermagementrevista, serviu para delinear o perfil da clientela. Chamo este $1^{\circ}$ passo, inserido na $2^{\mathrm{a}}$ fase, de "desvelando a cliente/ser humano", pois adentro em sua intimidade, conheço suas dificuldades, expectativas, sentimentos, aspirações, ansiedades, medos, através do histórico de enfermagem, o qual me permite desvelar o ser. O histórico possibilita identificar características pessoais, sócio culturais, biológicas, sobre a hospitalização, informações essas precisas, porém dinâmicas e flexíveis. Este momento facilitou o traçado do perfil das clientes/mães que amamentam as quais nomeei com denominações de ervas utilizadas em chás. Atribuí os nomes pelas características da erva e da cliente.

Assim, o primeiro passo, desvelando a cliente/ser humano, está íntimamente relacionado ao $2^{\circ}$ passo, resgatando características e prioridades, pois ao mesmo tempo em que desvelo, efetiva-se o cuidado a partir das necessidades ou prioridades detectadas. Este passo, inserido na implementação da sistematização do cuidado aponta aspectos relevantes de cada ser envolvido, delineando o diagnóstico de enfermagem, o qual está relacionado ao desvelamento da cliente/ser humano. Detecto que das quinze clientes que participaram deste trabalho, seis são adolescentes. Todas apresentam um perfil sócio-econômico desfavorável. Quanto ao tipo de parto entre as seis adolescentes, três realizaram parto normal e entre as nove clientes adultas, três realizaram parto normal. Ao continuar o $2^{\circ}$ passo, resgatando características $e$ prioridades de cuidado às mães que amamentam, optei em realizar entrevistas por considerar ser este, um instrumento para selecionar estratégias e ouvir a opinião de cada mãe envolvida. $A$ entrevista serviu para coletar os dados qualitativos. Quando questionadas sobre a importância do aleitamento materno exclusivo pode-se verificar que consideram este ato muito importante, sendo agente de proteção, saúde, amor, carinho e satisfação das necessidades do bebê.

A criança cresce saudável, inteligente e é bom, né! O leite materno é bem importante por causa dos métodos de inteligência, de saúde, de proteção de doenças, né! (Anis)

Para proteção das doenças, a criança sente-se mais amada tem muitas outras coisas, é um momento de carinho e amor que passa da mãe para o filho e do filho para a mãe também (Cidreira).

Porque o leite materno tem tudo o que o bebê precisa (Calêndula). 
Bem, é por causa da saúde né, o bebê que mama no peito é mais saudável, tipo ele combate as doenças. O leite materno é o melhor alimento que tem (Sálvia).

Ao serem questionadas sobre os sentimentos quanto a permanência do bebê junto à mãe, observa-se que as mães que amamentam, expressam com maior facilidade este aspecto. Os depoimentos apontam visões de ambigüidade ao relatarem sobre a permanência do bebê ao seu lado, explicitando que é difícil, mas ao mesmo tempo importante e melhor. Para algumas, oferece segurança, diminuem as angústias, facilitando os cuidados e a própria amamentação, bem como a vigilância constante do bebê. Expõem ainda a importância do contato mãe-filho desde o nascimento, fortalecendo os sentimentos afetivos maternos. Os relatos expressam:

É importante, mas é difícil, porque a mãe tem que recuperá e daí, tem que ficá lidando com o nenê, não é fácil... É importante ele ficá perto pra senti a presença da mãe... tem que senti carinho, tem que senti a temperatura da mãe (Sálvia).

Acho importante porque sei lá, não sei explicá, ah! Porque a gente pega mais amor e ele pega mais amor na gente e é bom porque ah! Porque é bom amamentá (Hortelã).

Eu acho bom, pelo menos e gente tá ali cuidando dele, trocando, tá junto com a mãe o tempo todo, porque eu acho que é o carinho que ele precisa na hora que nasce (Erva-doce).

Com relação ao aleitamento materno é mais fácil o nenê vim mamá e desce de novo, fica lá; eu preferia assim, porque desce, fica lá no berçário, depois sobe outra vez, dai a mãe tem mais chance de descansá (Sálvia).

Quando realizei a pergunta sobre as vantagens do aleitamento materno, foi possível perceber que as respostas são muito semelhantes ao primeiro questionamento da importância do aleitamento materno exclusivo. Na visão das mães que amamentam, a importância e vantagens estão inter-relacionadas, apontando para a conscientização sobre o aleitamento materno.

O leite materno é saudável para o bebê, evita infecção, doenças é bom para a mente (Anis).

É uma vacina, protege a criança das doenças e também faz bem para a mãe (Cidreira).

É bom para tudo, o crescimento, desenvolvimento e proteção do bebê (Avenca).

Durante a realização da entrevista questionei sobre "significado à mãe da primeira mamada". É possível apreender pelos relatos, que é motivo de emoção, alegria, amor, afeto, carinho, felicidade, poder da vida, aconchego.

A gente sente mais amor, mais carinho, se sente mais mãe, é um sentimento mais forte porque ele é retirado daqui, e a gente está sentindo ele saí daqui, encosta perto da gente realmente, é ter o poder da vida (Cidreira).

Aconchego com meu filho, o cuidado, me trouxe só alegria, emoção, a gente esquece até a dor (Anis).

Ao questionar às mães se receberam orientações sobre aleitamento materno na Unidade de Saúde ou outro local, 11 das 15 clientes relataram que sim e 4 salientaram que não.

Ao analisar todos os depoimentos percebe-se claramente que as mães que amamentam têm consciência da importância e vantagens do aleitamento materno, exteriorizando sentimentos 
de prazer e satisfação ao vivenciar este momento tão singular em suas vidas. Os dados revelam que, apesar de todos os esforços, ainda conta-se com mães que não participam das orientações, o que demonstra a necessidade de enfatizar a educação em saúde em todos os espaços onde se oferece cuidados à mulher. Pode-se inferir ainda, que ao efetivar a escuta atentiva enquanto ação de cuidado, é possível a aproximação ao ser mulher, seu conhecimento, bem como o desvelamento de seu mundo vivido. O cuidado humano torna-se um desafio em que a enfermeira necessita buscar novos referenciais de cuidado, novas maneiras para lidar com pessoas de diferentes culturas. O desafio também situa-se em conhecer diferentes formas de viver, os eventos de crise, a dinâmica de saúde, episódios de doença e outros fatores que o ser humano compartilha. Conhecer as particularidades, crenças e valores da cliente que cuidamos auxilia a enfermeira a desempenhar novos papéis com uma visão ampliada. As pessoas estão em mudança em um mundo de mudanças, e este movimento suscita na enfermeira a necessidade de buscar o novo, para cuidar destas pessoas. Serão mudanças multiculturais que exigirão um melhor preparo da enfermeira, com maior responsabilidade, respeito aos direitos humanos frente às diferenças e similaridades das clientes.

Iniciei, então, o planejamento do $3^{\circ}$ passo, o qual denominei estabelecendo o cuidado. Planejei o cuidado com a cliente/mãe, tendo sempre em mente que o ser humano é um ser singular, integral e indivisível. Neste momento, também os princípios éticos se realçaram, principalmente no que se referia à mobilização do meio ambiente com vistas a oferecer condições favoráveis à saúde. O planejamento ou estabelecimento do cuidado, pode ser realizado pelo enfermeiro/cliente, pelo enfermeiro/equipe de enfermagem e pela equipe de enfermagem /cliente. Concomitante ao estabelecimento do cuidado, deu-se a seleção das estratégias para as ações da enfermagem. Esta seleção aconteceu de acordo com as possibilidades de cada pessoa integrante deste processo. O desempenho de cada um foi singular e analisado no momento do planejamento do trajeto e da escolha das estratégias. Destas, algumas possíveis de utilização foram: cuidado direto ao binômio mãe-filho, medidas de prevenção de intercorrências, educação em saúde, apoio, reuniões com a equipe de saúde, escuta atentiva/estratégia de cuidado transpessoal, doação, responsabilidade, mutualidade, expressividade, comprometimento, envolvimento, empatia, respeito mútuo, compreensão, interação, comunicação, etc. Esse momento leva em consideração os passos anteriores em que entrelaçados, formam o todo necessário para o efetivo cuidado às mães em aleitamento materno. $O$ término da $\mathbf{2}^{\mathrm{a}}$ fase explicita as necessidades e prioridades do cuidado, porém ainda continua o processo, através da avaliação que deve ser contínua durante todas as etapas. Por ser um processo, está em constante movimento, colocando todas as fases e passos em atividade, resultando no conhecimento global da situação e conseqüente implementação do cuidado.

A $3^{\text {a }}$ fase, avaliando o caminhar da prática desenvolveu-se de maneira dinâmica, interligada e contínua através do acompanhamento da trajetória. Durante o percurso foi observado que as clientes/mães que amamentam, apresentaram mudanças significativas com relação as informações sobre o aleitamento materno. Percebo que hoje as mães estão mais conscientizadas sobre a importância do aleitamento materno e preparadas para manter essa prática por maior tempo possível. Percebo também, que os problemas precoces com as mamas, entre outros, diminuíram sensivelmente em relação a épocas anteriores. Tais fatos evidenciam a congruência das ações de enfermagem com as estratégias estabelecidas.

\section{CONSIDERAÇÕES FINAIS}

O trabalho não se propôs a idealizar e implementar apenas uma proposta de cuidar mas foi além, pois envolveu as clientes-mães que amamentam e também a equipe de enfermagem. Observo após concluir esta etapa, que é viável colocar em prática ações diferenciadas e inovadoras de cuidado. Os benefícios são visíveis a ambos, clientes e equipe de enfermagem. 
Considero que ao planejar uma proposta, visualizamos os pontos a serem atingidos, mas também os possíveis obstáculos que se colocam de forma até natural, a todo projeto novo. As reflexões grupais junto à equipe exigiu de todos um reaprender a conviver em grupo, pois foi necessário deixar de lado o cumprimento de tarefas para desenvolver a percepção e criatividade. O grupo tornou-se um instrumento de auto-ajuda, pois auxiliou na exteriorização de sentimentos, valores, conceitos, crenças e propiciou a oportunidade de repensar novas idéias e dimensões. As diversas partes que compõem o grupo, uniram-se para formar o todo e assim, crescer e desenvolver suas potencialidades. O caminhar coletivo constituiu a prática de cuidado, em que foram se desvelando facilidades, motivações, dificuldades e desinteresse. Considero que a união de vários esforços deu o impulso necessário para a implementação das estratégias estabelecidas e trouxe como retorno, a satisfação para toda equipe do alojamento conjunto, tanto no aspecto pessoal como profissional. A implementação da metodologia do cuidado, descrita nesta monografia, realizada durante o ano de 1999, contribuiu diretamente para a conquista do título "Hospital Amigo da Criança", recebido em 15 de março de 2000.

\begin{abstract}
The purpose of this study was to implement a nursing care proposal with an educational focus for breastfeeding mothers at a hospital in Curitiba, with the effective involvement of the nursing staff of the rooming-in unit. In order to achieve this objective, the ideas of Watson were used as theoretical background. Methodology involved the implementation of all steps of the nursing process. Conceptual building, systematization and evaluation of the care provided enabled to outline the conceptual landmark. In order to implement the steps of the proposal, meetings were carried out between mothers and nursing staff, as well as to gather data. Qualitative data methods were used to analyse the data. Fifteen (15) mothers participated in the study. The results showed that it was possible, along the study, to uncover their difficulties, wishes, anxieties, frustrations, emotions, expectations, fears, doubts, preconceptions and feelings of insecurity, discouragement, satisfaction and apathy.
\end{abstract}

KEYWORDS: breastfeeding, nursing care, nursing process

RESUMEN: El estudio se llevó a cabo en un hospital de Curitiba con el objetivo de implementar una propuesta de cuidados, dentro de un enfoque educativo, a las madres durante el período de amamantación reuniendo a todo el equipo de enfermería de la unidad. Para alcanzar esa meta utilicé como referencial teórico las ideas de Watson. La metodologia se basó en la operacionalización de todas las fases que componen el proceso de enfermería. La construcción de los conceptos, la implementación de la sistematización del cuidado y evaluación del camino recurrido posibilitaron delinear el marco conceptual. A través del desarrollo de esas etapas se efectuaron los encuentros entre las madres y el equipo de enfermería, los cuales sirvieron también para colectar datos. Se analizaron de forma calitativa. Participaron 15 madres. Fue posible desvelar sus dificultades, deseos, ansiedades, frustraciones, emociones, esperanzas, miedos, dudas, conclusiones anticipadas, inseguridad, desánimo, satisfacción e indiferencia durante el transcurso del trabajo.

PALABRAS CLAVE: Amamantamiento materno, cuidado de enfermería, proceso de enfermería

\title{
REFERÊNCIAS BIBLIOGRÁFICAS
}

BAGNATO, Maria Helena Salgado; COCCO, Maria Inês Monteiro ; SORDI, Maria Regina Lemes de. Educação, saúde e trabalho. Campinas: Alínea, 1999.

COCCO, Maria Inês Monteiro. A ideologia do enfermeiro: prática educativa em saúde coletiva 1991. 160p. Dissertação (Mestrado em Educação) - Universidade Estadual de Campinas, 
Campinas., 1991.

FREIRE, Paulo. Pedagogia da autonomia: saberes necessários à prática educativa. Rio de Janeiro Paz e Terra, 1997.

NUNES, Ana Maria Pereira ; ZAGONEL, Ivete P. Sanson. Cuidado humano e autocuidado: contribuição de Orem e Watson ao conhecimento da enfermagem. Cogitare Enfermagem, Curitiba, v.1, n. 1, p.28-33, jan./jun., 1996

SANTOS, Evanguelia Kotzias Atherino dos. A mulher como foco central na prática do aleitamento materno: uma experiência assistencial fundamentada na teoria do autocuidado de Orem. 1991. Dissertação (Mestrado em Assistência de Enfermagem) - Universidade Federal de Santa Catarina, Florianópolis, 1991

VALDÉS, V. ; SÁNCHEZ, A. Pérez ; LABBOK, M. Manejo clínico da lactação : assistência à nutriz e ao lactente. Rio de Janeiro: Revinter, 1996.

WATSON, Jean. Nursing: the philosophy and science of caring. Boston : Little Brown and Company, 1979

WOLFF, Lilian Daisy Gonçalves. A compreensão da experiência de ser cuidadora de enfermagem em uma UTI pediátrica. 1996. 136p. Dissertação (Mestrado em Assistência de Enfermagem) - Universidade Federal de Santa Catarina, Curitiba, 1996. 